\title{
Primary Healthcare Payer
}

National Cancer Institute

\section{Source}

National Cancer Institute. Primary Healthcare Payer. NCI Thesaurus. Code C70688.

A health plan or payer oblig ated to pay a healthcare service claim first. 